Chlamydial conjunctivitis was diagnosed more often in autumn than winter. There was no difference in birth rate in the health authority in these seasons. Others have found $C$. trachomatis conjunctivitis to occur more often in the fourth quarter of the year. The reason for this is unknown. ${ }^{6}$

Neonates are thought to acquire $C$. trachomatis during passage through the birth canal. In our study four babies with chlamydial conjunctivitis had been delivered by caesarean section in the presence of intact membranes. Both parents of two of these babies had $C$. trachomatis genital infection. This suggests that babies may acquire $C$. trachomatis by routes other than passage through an infected cervix, possibly by ascending cervical infection. Infants developing $C$. trachomatis conjunctivitis after caesarean section might, however, be infected after birth by their parents or by indirect contact with other infected infants.

Two babies of 26 seen after treatment had persistent discharge and $C$. trachomatis was reisolated from one $(4 \%)$. In another study $12 \%$ of 34 cases had persisting $C$. trachomatis after similar treatment ${ }^{7}$ As in this study, reisolation of C. trachomatis in our patient was associated with minimal discharge. Gonococcal ophthalmia is now thought to be rare in Britain. Our single case had concurrent $C$. trachomatis infection.

We believe that investigation of conjunctivitis in neonates should include specimens for $C$. trachomatis as well as bacteria. Parents of infants with chlamydial (or gonococcal) conjunctivitis should be investigated because $C$. trachomatis is a common cause of pelvic inflammatory disease and has important public health consequences.

The authors thank Syva UK for the supply of reagents, Lederle Laboratories for financial support, and Mrs Hanni Martin for her help in the preparation of the manuscript.

\section{References \\ 1 Prentice MJ, Hutchinson GR, Taylor-Robinson D. A micro- biological study of neonatal conjuctivae and conjunctivitis. $\mathrm{Br} \mathrm{J}$ Ophthalmol 1977;61:601-7. \\ 2 Pierce JM, Ward ME, Seal DV. Ophthalmia neonatorum in the 1980s: incidence, aetiology and treatment. Br J Ophthalmol 1982;66:728-31. \\ ${ }^{3}$ Molgaard IL, Neilson PB, Kaern J. A study of the incidence of neonatal conjunctivitis and of its bacterial causes including Chlamydia trachomatis. Acta Ophthalmologica (Copenh) 1982;62:461-71. \\ 4 Stenson S, Newman R, Fedukowiczs H. Conjunctivitis in the newborn: observations on incidence, cause and prophylaxis. Ann Ophthalmol 1981;13:329-34. \\ 5 Teare EL, Sexton C, Lim F, McManus T, Uttley AHC, Hodgson J. Conventional tissue culture compared with rapid immunofluorescence for identifying Chlamydia trachomatis in specimens from patients attending a genito-urinary clinic. $\mathrm{Br} \mathrm{J}$ Vener Dis 1985;61:379-82. \\ 6 Armstrong JH, Zacarias F, Rein MF. Ophthalmia neona- torum: a chart review. Pediatrics 1976;57:884-92. \\ ${ }^{7}$ Rees E, Tair IA, Hobson D, Karayiannis P, Lee N. Persistence of chlamydial infection after treatment for neonatal conjunc- tivitis. Arch Dis Child 1981;56:193-8.}

Correspondence to Dr A H C Uttley, Public Health Laboratory, Dulwich Hospital, East Dulwich Grove, London SE2 8QF.

Received 20 March 1986

\title{
Nutritional treatment of congenital heart disease
}

\section{BOUGLE, M ISELIN, A KAHYAT, AND J-F DUHAMEL}

Service de Pediatrie, CHU Clémenceau, and Service de Cardiologie Infantile, CHU Côte de Nacre, Caen, France

SUMmary Twelve of 13 patients with congenital heart disease given continuous enteral nutrition displayed normal growth; cardiac function remained stable or improved in 10 in spite of the water load $(146 \pm 22 \mathrm{ml} / \mathrm{kg} /$ day $)$. This is safe treatment for malnutrition in congenital heart disease.

Growth delay is commonly observed in infants with congenital heart disease. This seems to be due to both cardiac failure and malnutrition, whatever the nature of the malformation. ${ }^{1}$ In some cases malab- sorption has been found, ${ }^{1}$ but malnutrition is mainly due to poor voluntary intake..$^{1-3}$

Poor growth delays the surgical correction of the cardiac anomaly and can impede postoperative catch up growth, due to development of pulmonary hypertension. ${ }^{1}$

Few studies have attempted, however, to correct or prevent malnutrition in congenital heart disease. ${ }^{2-4}$

\section{Patients and methods}

We studied 13 patients admitted to hospital to 
improve their state before surgery. Four were neonates less than 2 weeks old (mean 11 days). The other nine were on average 14 weeks old (range 2-24 weeks). They presented either with cardiac failure or failure to thrive in spite of digitalis and diuretic treatment. Ten had ventriculoseptal defects, one supravalvular aortic stenosis, one a tricuspid atresia, and one abnormal implantation of the left coronary artery. The four children presenting with Down's syndrome also had heart defects but no other malformation.

The newborn infants still weighed less than their normal birth weight. Weight and height gains were expressed as a ratio of observed values to normal for age given by the Sempe chart ${ }^{5}$ to remove differences in growth rate due to age.

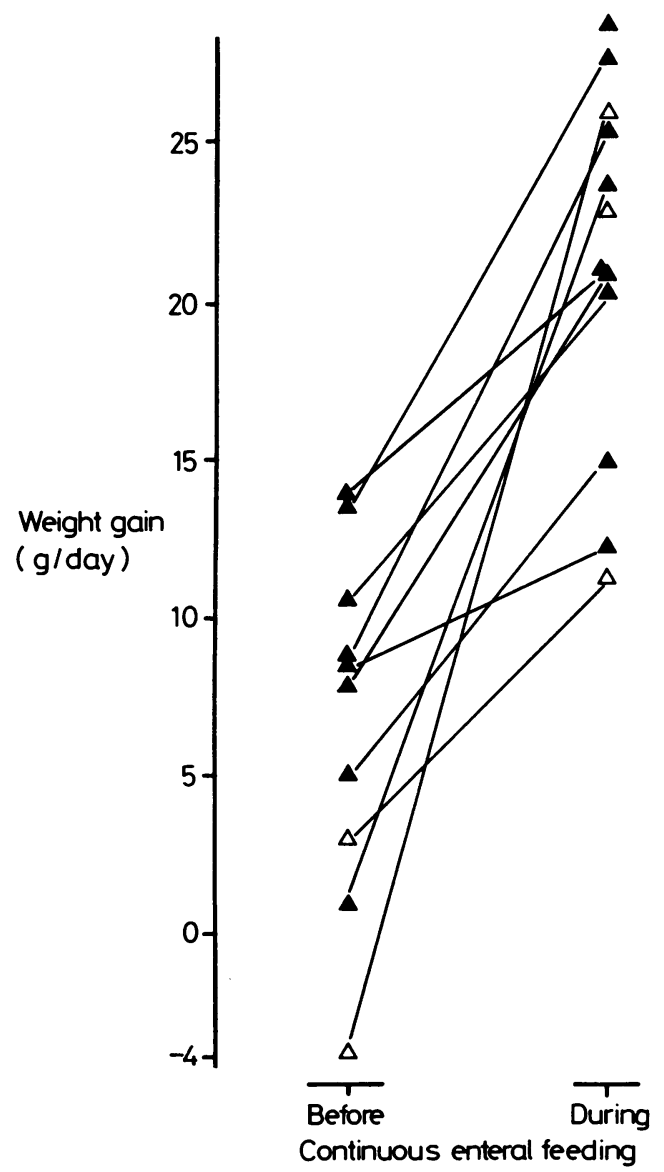

Fig. 1 Weight gain (g/day) from birth to admission to hospital $\mathrm{v}$ results of continuous enteral feeding. Open symbols represent children in whom the feeding had to be stopped for cardiac surgery.
Continuous intragastric infusion using an infant formula with added energy in the form of medium chain triglycerides and carbohydrate was started at a rate of $40 \mathrm{ml} / \mathrm{kg} /$ day and progressively increased until an increase in weight was observed. Infants were weighed daily and measured every two weeks. Infants who were fed by this method for less than two weeks were excluded. Height increase is shown for patients fed intragastrically for at least four weeks.

The differences between the first and last days of study were analysed by the non-parametric Mann and Whitney test.

\section{Results}

Feeding lasted for a mean (SD) of 40 (21) days and supplied a mean (SD) of $137(27) \mathrm{Kcal} / \mathrm{kg} /$ day in 146 (22) $\mathrm{ml} / \mathrm{kg} /$ day. Absolute weight gains are shown in Figure 1. Figure 2 compares weight and height ratios. Height growth before feeding, which could be calculated in only three infants, is not shown.

Only one infant on the feeding regimen had a growth below $10 \%$ of normal; surgical intervention

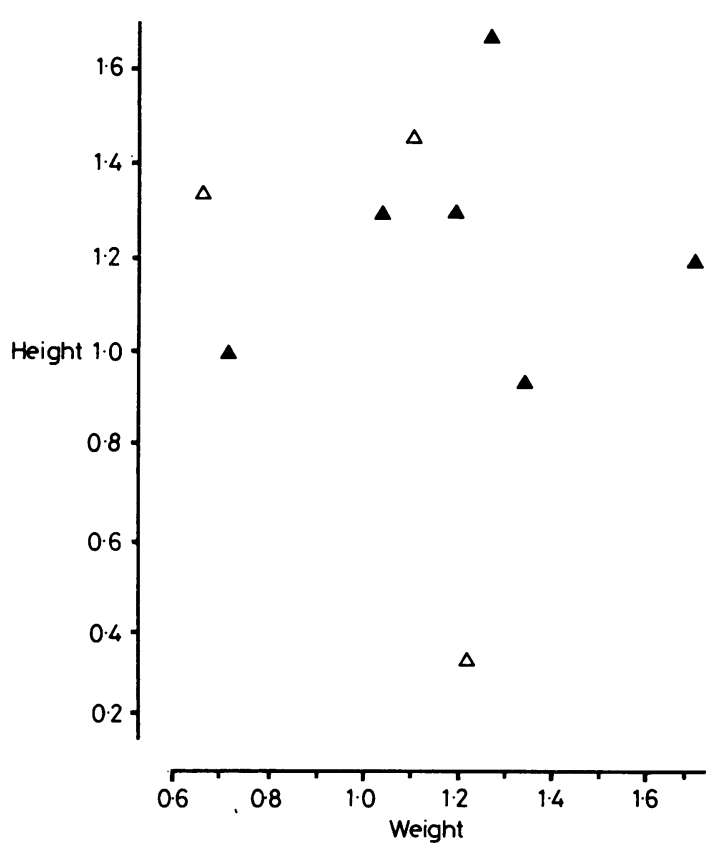

Fig. 2 Relative growth:height growth during continuous enteral feeding/ideal growth for age (height) $\mathrm{v}$ weight gain during continuous enteral feeding/ideal weight gain for age (weight). Open symbols represent children in whom the feeding had to be stopped for cardiac surgery. 
was necessary in this case because of persistent cardiac failure.

Cardiac outcome. The feeding regimen had to be stopped and cardiac surgery performed in three infants with complex cardiac lesions, one of whom died during surgery.

Nine infants benefited from the feeding until their nutritional state had improved enough to allow safe surgical intervention. One was sent home after cardiac failure had resolved.

\section{Discussion}

We report an attempt to prevent the development of malnutrition in infants with congenital heart disease. Our results clearly show that these infants do grow when given an adequate energy supply, even if they have complex lesions presenting with cardiac failure. This is therefore confirmation that cardiac failure delays growth mainly by reducing voluntary intake.

The weight gain was associated with normal growth in height in eight of the nine infants. This group of patients has good growth potential. We cannot exclude some water retention, yet none displayed gross oedema. A prospective study is in progress to assess body composition in these patients.

All our patients had types of congenital heart disease that usually preclude any increase of fluid supply. The feeding regimen had to be stopped, however, only in infants with congenital heart disease of poorer natural prognosis. Continuous enteral feeding may alleviate both fatigue due to sucking and periodic blood flow changes related to feeding. ${ }^{6}$

\section{Conclusion}

Continuous enteral feeding can be given to malnourished children with congenital heart disease even if they present with cardiac failure and will result in safer cardiac surgery.

\section{References}

${ }^{1}$ Nadas AS, Rosenthal A, Crigler JF. Nutritional considerations in the prognosis and treatment of children with congenital heart disease. In: Suskind RM, ed. Textbook of pediatric nutrition. New York: Raven Press, 1981:537-44.

2 Krieger I. Growth failure and congenital heart disease: energy and nitrogen balance in infants. Am J Dis Child 1970;120: 497-502.

${ }^{3}$ Gingell RL, Pieroni DR, Hornung MG. Growth problems associated with congenital heart disease in infancy. In: Lebenthal E, ed. Textbook of gastroenterology and nutrition in infancy. New York: Raven Press, 1981:853-60.

4 Vanderhoof JA, Hofschire PJ, Baluff MA, et al. Continuous enteral feedings: an important adjunct to the management of complex congenital heart disease. Am J Dis Child 1982;136: 825-7.

5 Sempe M, Pedron G, Roy-Pernot MP. Auxologie, methode et séquences. Theraplix 1979.

${ }^{6}$ Nowicki PT, Stonestreet BS, Hansen NB, Yao AC, Oh W. Gastrointestinal blood flow and oxygen consumption in awake newborn piglets: effect of feeding. Am J Physiol 1983;245: 697-702.

Correspondence to Dr D Bougle, Service de Pediatrie A, CHU Clémenceau, 14000 Caen, France.

Received 11 March 1986

\title{
Hereditary multiple glomus tumours
}

\author{
S W BEASLEY, J MEL, C W CHOW, P G JONES
}

Departments of Surgery and Anatomical Pathology, Royal Children's Hospital, Melbourne, Australia

SUMMARY A 9 year old girl presenting with multiple glomus tumours is reported. Multiple glomus tumours are rare, often asymptomatic lesions, with a familial tendency and found in a more proximal location than their solitary counterparts. In our report four close relatives had similar lesions. Indications for surgical excision are discussed.

Glomus tumours are usually solitary, painful, and found in the distal extremities, classically under the nails. More recently, however, it has been recognised that multiple glomus tumours may occur as bluish swellings with a more proximal location. ${ }^{1-3}$ Multiple glomus tumours are extremely rare, and by 1971 only 45 cases had been reported. ${ }^{4}$ Characteristically, the tumours are asymptomatic, although a patient may have both painful and painless lesions at the same time. They occur with greater frequency in children than in adults but remain less common in all age groups than their solitary counterparts. ${ }^{1}$ Several authors have recorded a familial tendency in some cases of multiple glomus tumours with an autosomal 